\title{
Learning as a Merged Phenomenon of the Learner and the Content to Be Learned
}

\author{
Mona Holmqvist Olander ${ }^{1,2}$, Per Selin ${ }^{1}$ \\ ${ }^{1}$ Faculty of Education, University of Gothenburg, Gothenburg, Sweden \\ ${ }^{2}$ Faculty of Education and Society, Malmö University, Malmö, Sweden \\ Email: mona.holmqvist@mah.se,per.selin@edu.boras.se \\ Received 10 January 2016; accepted 3 July 2016; published 7 July 2016 \\ Copyright (C) 2016 by authors and Scientific Research Publishing Inc. \\ This work is licensed under the Creative Commons Attribution International License (CC BY). \\ http://creativecommons.org/licenses/by/4.0/ \\ (c) (i) Open Access
}

\begin{abstract}
This paper aims to contribute to knowledge of education based on a non-dualistic perspective on learning, by considering how a variation theoretical perspective seeing learning as a merged phenomenon of the learner and the object to be learnt affects instruction. In this project, teachers' theoretical non-dualistic awareness was developed through the introduction of variation theory as a guiding principle during a school-based research project. Based on a non-dualistic epistemological standpoint, the analysis focuses on the characteristics of instruction and learning from an assumption that the learner and the content learned cannot be separated. The data used for the analysis is from an example of instruction on learning to communicate in a foreign language. The analysis aimed to answer the questions: How do teachers orientate learners, carry out teaching and consolidate learners' knowledge? And how does this non-dualistic standpoint affect assessment? The results show in what way teachers transform and enact the curriculum objectives in teaching activities based on the learners' perspectives, which in turn describes how they change their way of assessing the students' learning in line with the theoretical assumptions by testing context-situated video-recorded group assessment, which are individually analysed.
\end{abstract}

\section{Keywords}

Non-Dualism, Variation Theory, Language Acquisition, Instruction, Learning

\section{Introduction}

This article contributes to the discussion about the nature of knowledge when learning based on a perspective seeing learning as a merged phenomenon of the learner and the content to be learnt. More specifically we respond to the discussion about epistemological dualism and non-dualism regarding the separation between the learner and what is to be learned, based on a variation theoretical perspective (Marton, 2015). The analysis in 
this article is based on an example from school, namely learning to communicate on a foreign language. Parts of the data set (the meetings) have previously been used to analyze what actions the teachers' have planned for when transforming new curriculum goals into teaching (Selin \& Holmqvist Olander, 2015), while the data in this study has been used to unveil trajectories of teachers' theoretical awareness of a non-dualistic approach teaching and learning. Shawer (2010) describes how communicative language teaching enhances learning, but calls for further research to examine the quality of teacher training and professional development, in addition to teaching styles. Assessing student learning in relation to teachers' instruction is suggested as a way of strengthening future research in this area. By that, this project not only contributes to knowledge about how instruction based on a non-dualistic perspective on learning is enacted in the classroom but also in what way this teaching style affects student learning.

\section{Theoretical Assumptions on Dualism and Non-Dualism}

The main difference between seeing the learner and what is to be learnt as two separate entities or as one merged phenomenon lies in how we are seeing the content. It could be defines as the same however is experiencing it or differently depending on who is experiencing it. If we see the content separated from the learner, the instruction will be based on a dualistic perspective. The way of separating physical (the content as such) from the psychological (our experiences of it) has its roots far back. The origins of the dualistic phenomenon can be traced back to Descartes' in the $17^{\text {th }}$ century, who presented the notion of dualism of mind and body (Damasio, 2010), dividing the human being into physical and psychological components. This has had important implications for society and science ever since. Lately, it has been claimed that Descartes himself did not really believe in the standpoint proposed. He may have done so to "offset possible religious persecution" (Damasio, 2010: p. 193). There seem to be two faces of Descartes, one before 1633 which is non-dualistic and another after that date which is dualistic. Krikeben (2010) points out sections of Descartes' work prior to 1633, which indicate a clear relation between the immaterial soul and body, rather than a separation between them. Whether or not this ontological point of departure was in response to society or Descartes' own deeply held belief, the separation he described influenced worldviews, both then and now, and is still discussed today. In this study we analyze what happens when teachers plan and conduct instruction which challenges a dualistic way of thinking.

The dualistic standpoint has a prominent epistemological place in many theories about learning. Descartes' (possibly tentative) thoughts about dualism (body and mind) have become entrenched in society, showing how views are open to influence and how thoughts can come to be widely held as the truth given the right place at the right time. However, as James (1907/2014) discusses the nature of truth from a perspective of pragmatism, society determines what is considered to be the truth in a specific context and time that different kinds of 'truth' have been developed:

"The pragmatist clings to facts and concreteness, observes truth at its work in particular cases, and genera-

lizes. Truth, for him, becomes a class-name for all sorts of definite working-values in experience.” (James 1907, p. 68).

In Descartes' case, the separation between body and mind has been considered to be 'truth', although we do not have any answer if there actually is a separation between body and mind. Instead, his dualistic perspective had important religious implications. The idea that the soul left the corpse, with the chance to reach a higher form of existence also provided opportunities to control the lives and actions of people on earth. This could have be explained in many other ways, but Descartes' assumptions were widely spread and accepted. Descartes' tentative proposal follows what James described regarding how truth is constituted, i.e. working-values which were generalized and became truth. However, James' work is also based on a dualistic point of departure in pragmatism. He follows the definition of Peirce:

"To attain perfect clearness in our thought of an object, then, we need only consider what conceivable effect of a practical kind the object may involve-what sensations we are to expect from it, and what reactions we must prepare. Our conception of these effects, whether immediate or remote, is then for us the whole of our conception of the object, so far as that conception has positive significance at all. This is the principle of Peirce, the principle of pragmatism.” (James 1907, p. 47).

Dualism and non-dualism have lately also been an issue in the theoretical framework of pragmatism. Pragmatism has become well-known and is frequently referred to by teachers as Dewey's (1998) "learning by doing”. It 
can be claimed to fulfill its aim to be “what works” (Morgan, 2014). However, Dewey developed a set of his own assumptions, different to those of the Cartesians, regarding the abstract representation of knowledge. Instead of seeing truth as something abstract created by the mind, a reflection of the outside world, Dewey saw knowledge as something to be discovered, beliefs that must be considered in relation to their practical consequences (Sundin \& Johannisson, 2005). The neo-pragmatism movement takes this idea further and introduces an anti-dualistic stand, assuming a strong relation between language, knowledge and the world, where language replaces the distinction between reality and appearance (Sundin \& Johannisson, 2005). Language and the ability to see oneself from the perspective of others are claimed to be what distinguishes human beings from other animals. Is the non-dualistic perspective of the world only possible for human beings or do human beings more easily accept a dualistic perspective? This provides two new challenges: the strong focus on a distinction between humans and animals in the tradition of the theoretical framework underpinning Dewey’s work (Bakhurst, 2009; Dewey, 1998), and the deviation from practical social democratic projects (Danisch, 2013). The claim that humans are different because they are the only beings that can reflect on themselves through the eyes of another and use language in a reflective way, has been questioned (Bakhurst, 2009; de Waal, 2008). Findings from de Waal (2008) show that apes, at least, have empathy at the level of sympathetic concern. He writes:

"Concern for others is different in that it relies on a separation between internally and externally generated emotions. (p. 284) [...] For an individual to move beyond being sensitive to others toward an explicit other-orientation requires a shift in perspective. [...] A heightened self-identity allows a subject to relate to the object's emotional state without losing sight of the actual source of this state (p. 285)”.

Mirror self-recognition (MSR) is the ability to recognize oneself in a mirror, i.e. knowing where a mark on the face seen in a mirror corresponds with placement of the mark on one's actual face. It has been found in different species: apes, dolphins and elephants (de Waal, 2008). However, social interaction and language among animals is difficult for humans to study as we do not have access to their way of thinking and communicating. We risk missing evidence of their abilities as we cannot imagine how their skills are manifested. We are limited to study other species based on our own terms. In fact, as we can never step outside being human, our understanding about the world is restricted. Stepping outside oneself is only possible within our own species, which strengthens the non-dualistic assumption. When we judge other creatures, we require them to understand our perspective as we only offer them our ways of understanding the world, not theirs. We can only reflect on knowledge developed in a historical context based on our condition over time. In the light of recent research, some assumptions made about animals become odd. For example, Marx claimed that animals cannot distinguish themselves from their 'life-activity' or make critical reflections as they cannot step outside themselves. He suggested that human beings can see themselves through the eyes of another and reach self-transformation in a way we do not see in animals, which gives humans a superior status over all other life on Earth (Bakhurst, 2009). However, this is only true when we relate this to our own species. Maybe other species lives more naturally in a non-dualistic perspective on the world than human beings do, but this question seems to be impossible to answer.

In this article we instead ask whether it is true that human beings can step outside and reflect on themselves in the light of others' views? Is such reflection possible at all, given that we can only reflect on ourselves based on our own way of understanding others' understanding of ourselves? Is this really 'to step outside yourself'? Results from eye-tracking studies have found that humans derive their first gist of a phenomenon in a subconscious way after just a few milliseconds. This informs our viewing pattern and helps determine where to direct our subsequent focus (Holmqvist Olander, Wennås Brante, \& Nyström, 2014). This subconscious guidance is further evidence for the non-dualistic standpoint. It seems impossible to separate body and mind when we consider how the body is able to assess particular situations at a subconscious level, and then use this to change conscious thinking, as well as the other way round. So maybe human beings are not that superior to other species.

\section{A Non-Dualistic Point of Departure for Learning}

A non-dualistic epistemological point of departure for learning differs from assumptions held by theories which explain learning as either a result of the responses we get from the environment or something inherent, related to the development of the human brain. Our discussion is about how we consider learning as a merged phenomenon of both learning and content, impossible to separate, based on the discussion above. In this paper, we offer an analysis based on a non-dualistic framework called variation theory. We describe the transformation of formal curricular goals into classroom instruction, considering different ways in which lessons are designed based on 
the students' initial understanding of the learning object. The effect of the transformation is evaluated based on assessment of students' learning outcomes, to indicate how the learners' views of the content change. One of the many ideas about assessment of learning outcomes is that there must be alignment between construct-an indicator or manifestation of a hypothetical creation - and the curriculum standard, which would be the hypothetical creation, that this construct is supposed to assess (Wolf et al., 2008).

This project focused on the teaching and learning of English as a foreign language (EFL). Shawer (2010) describes how communicative language teaching enhances learning, but calls for further research to examine the quality of teacher training and professional development, in addition to teaching styles. Assessing student learning in relation to teachers' instruction is suggested as a way of strengthening future research in this area. In this project, teachers' theoretical awareness was developed through the introduction of variation theory as a guiding principle. The way teachers manage content in relation to learners' learning outcomes was analysed. We start by describing variation theory.

\section{Variation Theory as a Non-Dualistic Perspective on Learning}

Learning is defined by Marton and Booth (1997) as becoming aware of the world in a qualitatively new way. To be aware is explained as being conscious of some critical features of an object while its other features make up the background. Variation theory studies focus on the object of learning, which can be realised in different ways and separated into three types (Marton et al., 2004; Lo, 2012). The intended object of learning is what a teacher plans and intends for learners to learn. This space of learning is seen from the teacher's point of view. This means in what way teachers make it possible for students to learn the content to be learnt by creating variation of its parts, possible for all students to discern. From an outsiders' point of view (e.g. an observing researcher) the enacted object of learning can be seen, and this is what matters when it comes to considering what is possible to learn in school (Marton et al., 2004). Through the enacted object of learning, other parts of the school world, such as curriculum and the teacher's intentions, are communicated since that is what actually happens in the classroom. However, all the things that it is possible to learn in a particular situation are seldom understood and made sense of by learners. The lived object of learning is what is experienced and assessed by pre-and post- tests. An analysis of the relationships between different types of objects of learning helps us to understand learning through awareness of the learning that is made possible. Learning in this perspective should be understood as a result of the students' qualitatively developed way of understanding the phenomenon to be learnt, not in terms of cause and effect, but through a merge of the learner and object of learning. This is analogous to the non-dualistic stance outlined. Learning is understood from the second-hand perspective of the learners' experience of content, and not from the first-hand perspective of the content.

Our research is based on data from an iterative model for studying children's learning (learning study) (Marton \& Tsui, 2004). The model is a tool for teachers' use, through which they can transform curriculum objectives into classroom practice. Learning outcomes are analyzed in relation to teachers' instruction in the classroom. Our discussion addresses three main questions:

1. What characterizes an analysis of instruction based on a non-dualistic epistemological standpoint?

2. How is the non-dualistic perspective expressed at three levels of analysis (orientation, consolidation and act)?

3. In what way can the analysis of student learning indicate traces from the non-dualistic epistemological framework?

\section{Methods and Analysis of Data Collection}

Pragmatism, as defined by James (1907/2014) and Pierce (1905/1998), stresses the need for practical bearings for all statements. The theoretical discussion at the outset of this paper has been tested in practice to determine if the non-dualistic assumption about learning influences teaching and learning. There is a strong need for educational research to not only explain learning, but also to develop powerful learning situations regarding students' improved learning outcomes that can contribute to societal development (Pring, 2015). Our empirical data comes from a case study in the field of educational research design (McKenney \& Reeves, 2012), namely the iterative model learning studies (Marton \& Tsui, 2004; Marton \& Pang 2005; Holmqvist, Holmquist, \& Cheung, 2010; Kullberg, 2010; Holmqvist, 2011; Runesson, Kullberg, \& Maunula, 2011) undertaken during the 2012- 2013 school year. Learning study includes the collection of mixed-method data (Morgan, 2014; Yin, 2014), and is an approach that includes planning, performing, assessing and evaluating teaching (Pang \& Lo, 2011). It is a cyclic 
process that takes its structure from the Japanese lesson study approach (Lewis, Perry, \& Murata 2006; Dudley, 2012), in the field of educational action research (Hammond, 2013). It also has similarities with Dewey's model of inquiry described by Morgan (2014). In the learning study approach, a group of teachers plan, carry out and evaluate a restricted amount of content from the curriculum. Done collectively, this process is more likely to benefit learners and teachers. The approach brings a theoretical framework for learning (variation theory, Marton \& Booth, 1997; Marton, 2014; Ling \& Marton, 2012) based on a non-dualistic epistemological assumption. During instruction the teacher merges the structure of the content with the learners exposed to it. The design of the lessons aims to guide the learners' knowledge to new, merged experiences qualitatively more developed than before. The unit of analysis is the learning study process, and the analysis focuses on the treatment of the object of learning. The teachers' efforts to make the object of learning meaningful for the students, by merging the formal meaning in the curriculum with the students' own experiences of it, are analysed based on a non-dualistic perspective (variation theory)at three levels; orientation, consolidation and act.

\subsection{Procedure}

The study takes place in a context where a national standardized curriculum has to be followed, though the interpretation and implementation must be done by the teachers. An area of teaching was selected, and in that area a certain content- the object of learning - crystallized, either through interviews with learners or through experience of the teachers. Teachers' meetings and student interviews were recorded. A pre-test was administered, followed by a lesson, or a series of lessons, to teach this element. Afterwards, a post-test was conducted to determine whether or not the teaching was effective. The dataset comprised the discussions during the meetings, results of the pre-and post-tests, and video-recordings of the lessons. Analysis was undertaken at three levels of action based on how the object of learning was handled: 1) Orientation: the teachers compared the curriculum objectives with their own teaching experiences to merge and define the meaning of the formal text to develop an understanding of its sense (content focused); 2) Consolidation: the teachers define how to achieve the goals in relation to the learners'prior knowledge (student focused); and 3) Act: the teachers take steps to bridge the gap between students' pre-and required knowledge, which is measured to indicate the impact of the act. While steps one and two follow a linear pattern, the third step is cyclic. Within the subject of EFL, the specific content was the learning of oral communication strategies.

\subsection{Material and Method}

The analysis was based on seven recorded meetings with the participating teachers $(n=7)$ (Selin \& Holmqvist Olander, 2015), three video-recorded lessons in three different classes and three tests taken by each of the participating 29 learners (aged 13 - 15 years) in school years 7 - 9. In total, 87 tests were analysed in three steps: 1) after each activity; 2) in total as a group, and 3) based on the three levels of action.

The study was conducted in a secondary school in the west of Sweden. The school is situated on the outskirts of the municipality and learners come mainly from three small villages. The number of children in the school with a mother tongue other than Swedish is low (less than 5\%). EFL lessons are undertaken in year 8. Classes are split into two, with one half having an English lesson (the research lesson) and the other half an ICT class. This is routine practice throughout the school year, not only for the project. Altogether there were three research lessons with three different groups of learners from three classes. The teachers in the research group comprised all the teachers at the school who teach English. Not all of them were involved in the actual teaching, but they all took part in the planning and analysis of the lessons.

\section{Results}

The focus of the analysis was on how a non-dualistic assumption is expressed in classroom practice. Figure 1 describes the activities that took place. This is followed by an analysis of the activities.

\subsection{Defining the Object of Learning}

The initial meeting, the orientation level, focused on the curriculum text-“the ability to adapt use of language to different situations, purposes and recipients" (National Agency of Education, 2011: p.2). Teachers agreed that the learners need to be taught help-seeking communication strategies in real life contexts, e.g., formulaic sequences such as “Excuse me, where is...?” and "Do you know where...please?” Learning to use these phrases 


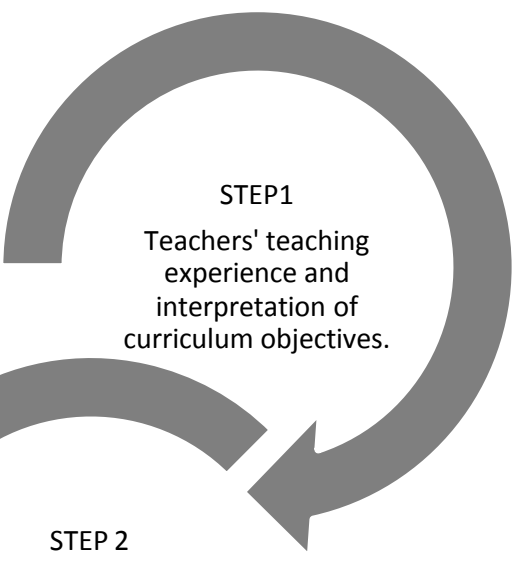

Evaluation of students' knowledge and definition

of learning goals to achieve.

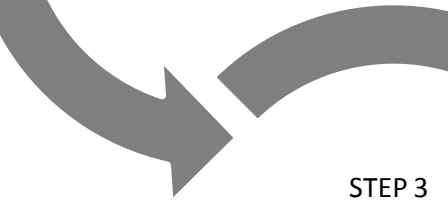

Implementation of lesson 1 , revision of the lesson based on the learning outcome.

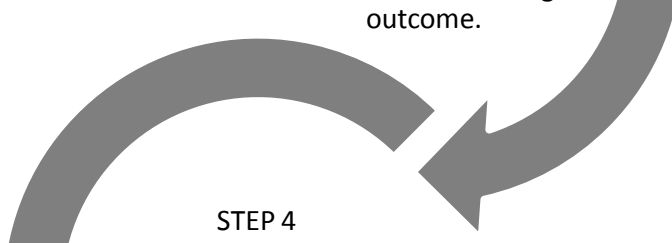

Implementation of lesson

2 , revision of the lesson based on the learning outcome.

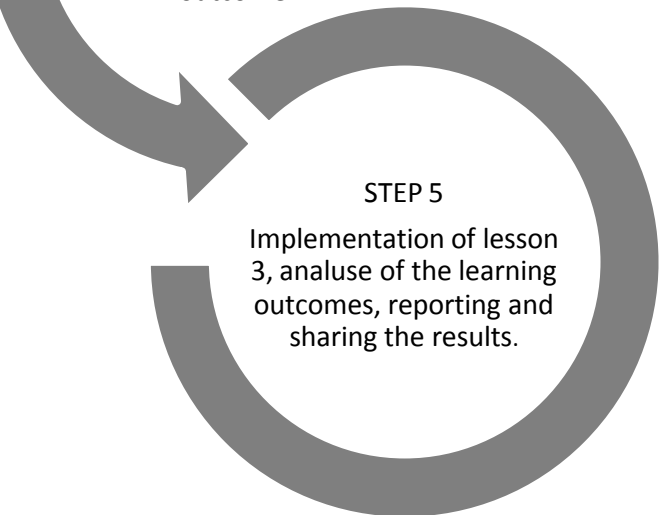

Figure 1. Flowchart of the activities taking place when teachers translated the new curriculum objectives into teaching and learning.

would lead to the children meeting the criteria in the curriculum, as well as developing an ability to communicate in real situations outside school. The non-dualistic assumption, that the object to be learnt and the learner's experience of it, is clearly expressed. The teachers take into consideration the learners' way of discerning the con- 
tent and gradually try to merge it with the way the content is described in the curriculum, focussing on "what is it I do not know when I do not know?” Teaching the object of learning explicitly takes the learners' understanding of it into account. During consolidation, the teachers decided to detail the intended message for communication, and the message sender and receiver. These aspects were pointed out at the same time, with different exemplars for different learners. When merging the three aspects (message content and both interlocutors) they did not assume that all learners would understand the content in the same way. They decided to act in a way that would take into account the learners' differing views of the content. At the consolidation level, the teachers decided to assess learning outcomes by recording their learners' communication and analysing it qualitatively based on the nature of communication, instead of defining their answers as simply right or wrong.

\subsection{Analysis of Lesson 1}

Discussion focused on ways of seeing the content instead of defining the learning outcomes as right or wrong. Nine of 10 children varied their language according to interlocutor and situation in the post-test. Recordings of the test were used for a qualitative assessment made by the teachers, who listened for usage of different phrases addressed to different interlocutors (peers, grown-ups, strangers), capturing the learners' discernment of the content. At the level of act, the discussion of the enacted object of learning focused on the extent to which the learners were introduced to and invited to enter their roles as 14-year-olds, strangers and teachers, to make the communication even more effective. This aimed to make the learners aware of their own communication by contrast with others, ultimately using such differences to further develop their skills.

\subsection{Planning Lesson 2}

Learners need to discern the critical aspects of introducing and addressing others. One way of achieving this goal was to keep a simultaneous focus on interlocutor and structure. Again, the teachers acted on a non-dualistic assumption regarding the content and the learners' ways of seeing it as inseparable. This was seen as important in transforming the goals of the curriculum, and was facilitated by allowing learners to have a more thorough introduction to their roles. The teachers found that children benefited from identifying closely with the characters they were intended to play. It was agreed that this would change from Lesson 1 to Lesson 2.

At the consolidation level, the discussion focused heavily on the roles the learners had played and how these could be made as true to life as possible. One of the teachers said: "If you act as somebody you must know how this person is. There is no possibility of acting as a 14-year-old or a grown-up unless you understand or have been made to understand how somebody like that is". The evaluation of the lesson showed that this perspective enabled the content and the learners' way of seeing it to be merged.

\subsection{Analysis of Lesson 2}

The discussion and analysis following Lesson 2 centred on the learners' opportunities to discern the dimension of variation in their language according to the interlocutor and situation. The focus was on the learners' perspectives of the content and was not divided to give a separate focus on only content or learner. The teachers found that, from the learners' point of view, a focus on the interlocutors was lacking. It was agreed that this could be because, as was intended, there was a stronger focus on the speaker's role. It could also be because the teacher did not explicitly say that the three different ways of asking for items or directions were ordered in terms of formality, and should be used while interacting with different interlocutors.

\subsection{Planning Lesson 3}

The supervisor introduced discussion about the interaction and dimensions of variation. The teachers seemed to assume that the differentiation between aspects varied, but that aspects themselves were invariant. As they had two lessons to compare, it was possible to consider different outcomes of different lesson designs. To see what it means for learners when they vary communication and interaction depending on the interlocutor and situation, it was useful to consider what happens when no variation occurs. Learners needed to be introduced, not only to the roles they were playing, but also to the roles of people with whom they were interacting. This would bring the lesson closer to the curriculum text, in which interaction, and not acting, is central. It was also focused on avoiding a separation of the content taught from the learners' views of it. 


\subsection{Analysis of Lesson 3}

The discussion that followed the final lesson also served to summarize the entire project. The teachers seemed glad to have learnt to implement curriculum goals and assess how these were transformed into content and understood by the students. One of the teachers said that she "reasoned about critical aspects in other lessons and subjects as well.” The nature of this reasoning is vague, but the teacher's comment indicates that there are particular features of an object of learning that must be understood in order for learners to have a chance of understanding the entire object of learning. The teachers also expressed ideas about understanding curriculum text in a new way. "It is not until you actually see it [a specific piece of teaching] performed that you can analyse it and compare it to the course plan," one of the teachers said in summing up the study. The content covered and the learners' different ways of seeing it were considered as equally important during their acts. The transformation was visible throughout the lessons. The study showed how the teachers interpreted and enacted the curriculum objectives in teaching activities based on the learners' perspectives. Their instruction was underpinned by a non-dualistic view, which considered the learners' perspectives merged together with the structure of the content taught.

\section{Discussion}

The aim of this study was to contribute to the discussion about the nature of knowledge using a perspective of learning as a merged phenomenon of the learner and the content to be learnt. This discussion is based on a non-dualistic epistemological standpoint, specifically variation theory. Our case study relates to the transformation of national curriculum goals for classroom instruction. Based on the pragmatic standpoint which demands practical implications for all statements, this study about learning requires data about influences on teachers' practical work. These will be discussed in relation to the research questions of the study.

The first research question asked: What characterized an analysis of learning based on a non-dualistic epistemological standpoint? The areas of focus were content, learner knowledge, implementation, and seeing the content from the views of the learners. Even where the curriculum is standardized, it still requires an analysis by teachers to define what is meant and how to understand the objectives. This seems to be linked with the teachers' own experience of teaching, and through this process new directions are developed to reflect the traditions of teaching in the specific subject. Interpretation of the new goals is incorporated into teachers' previous teaching experiences and is in this way assimilated with what is already practiced, as pointed out at the orientation level of analysis. At the consolidation level of analysis, the second alignment of curriculum objectives is in relation to learners' previous knowledge and what it seems possible to achieve when bridging the gap between the teachers' definition and the evaluation of learners' knowledge. Here teachers were the authority, and their way of interpreting the curriculum decided what was offered to learners. However, it was based on the learners' ways of seeing the content. Once teachers reached this step, they started to study how instruction could be designed to fulfill their aims as much as possible, shown in their acts. The results of this study suggest that teachers are active in the reformulation of the curriculum, and that their professionalism is visible in the process. It can also be seen, following Wolf et al. (2008), which the alignment between construct and curriculum is important when deciding which parts of learning should be assessed. The results show how teachers take the learners' perspective of the content into consideration in planning, enacting and assessing the content taught.

The second question concerns how the non-dualistic perspective is expressed at three levels of analysis (orientation, consolidation and act). The teachers read literature, discussed and collected data to define the curriculum goals, and assessed learners' knowledge using tests and interviews as part of orientation. They defined their understanding of the curriculum objectives in relation to findings about the learners' knowledge. The gap between what they wanted to achieve and what had already been achieved needed to be bridged. How that could be achieved was discussed and consolidated. After this step, they acted by following the process offered by the model used (learning study), which included pre-test, instruction, post-test, revision, and a new implementation of a lesson with a new group of students in order to identify effective ways of improving the learners' knowledge. The teachers' planning sessions served as communities of learning.

This leads to the third question, namely how to assess whether the objectives have been met in a satisfactory manner, and in what way the analysis of student learning can indicate traces of the non-dualistic epistemological framework. The teachers decided to use verbal evaluation at a group-level. They were very engaged in assessing the students' perspectives of the content taught, not only what content knowledge the students acquired. The qu- 
alitative assessment of the students' communication was argued for by the teachers seeing the individuals and the communication, the learner and the content learnt, as a merged phenomenon. Instead of separating the learning from its context by giving the students traditional individual tests, they video-recorded the students' communication and used a group assessment activity to inform their understanding of how to teach and design instruction of the content.

The analysis of the learning objectives focused on the non-dualistic nature of knowledge, which implies that content cannot be interpreted in an equal way. As the learners' different views of the content should be taken into consideration, the teachers' views of the objectives of the curriculum have to be differentiated. The question of equality in education is still a challenge which is likely to remain unsolved regardless of what we do. There is no such thing as objective understanding as long as we are human beings and limited in our capacity to understand within the realms of our experience and abilities.

Finally, what bearing does this study have on learning outcomes? There is a risk of assessing learning outcomes in line with the assumptions held by the teacher, regardless of whether these are theoretically motivated or not. If I see learning developing through participation in a communicative context, I will probably define communication as central to the assessment of learning. Alternatively, if I see activity as central, the way learners' engage in activities will be the main focus of assessment. In this case, learners' communication skills were assessed (rather than formal language skills) in line with the learning objectives. The limitations of the study address the small group of students, and replicating the study to verify the results has to be done including other students and subjects. There is also a need for future research to see if teachers who base their assessments on different perspectives of learning, assess the same skills and learning outcomes given the same content. This is another issue that has important implications for policies about educational equality.

\section{Acknowledgements}

This project is funded by the Swedish Research Council (project number 2011-5273), for which we are grateful. The project is also supported by University of Gothenburg. We would also thank all the participants for their contribution to the study. Finally, we would like to thank the anonymous reviewers for their important comments at an earlier manuscript which were very valuable.

\section{References}

Bakhurst, D. (2009). Reflections on Activity Theory. Educational Review, 61, 197-210. http://dx.doi.org/10.1080/00131910902846916

Damasio, A. (2010). Descartes Error Revisited. Journal of the History of the Neurosciences: Basic and Clinical Perspectives, 10, 192-194. http://dx.doi.org/10.1076/jhin.10.2.192.7250

Danisch, R. (2013). The Absence of Rhetorical Theory in Richard Rorty’s Linguistic Paradigm. Philosophy and Rhetoric, 46, 156-181. http://dx.doi.org/10.5325/philrhet.46.2.0156

de Waal, F. (2008). Putting the Altruism Back into Altruism: The Evolution of Empathy. Annual Review of Psychology, 59, 279-300. http://dx.doi.org/10.1146/annurev.psych.59.103006.093625

Dewey, J. (1998). Experience and Education. West Lafayette, Ind.: Kappa Delta Pi.

Dudley, P. (2012). Lesson Study Development in England: From School Networks to National Policy. International Journal for Lesson and Learning Studies, 1, 85-100. http://dx.doi.org/10.1108/20468251211179722

Hammond, M. (2013). The Contribution of Pragmatism to Understanding Educational Action Research: Value and Consequences. Educational Action Research, 21, 603-618. http://dx.doi.org/10.1080/09650792.2013.832632

Holmqvist, M. (2011). Teachers’ Learning in a Learning Study. Instructional Science, 39, 497-511. http://dx.doi.org/10.1007/s11251-010-9138-1

Holmqvist, M., Holmquist, P.-O., \& Cheung, W. M. (2010). The Same Lesson in Two Different Cultures-What Differs and What Is the Same? A Learning Study on Reading Comprehension in Sweden and Hong Kong. Problems of Education in the 21st Century, 21, 71-82.

Holmqvist Olander, M., Wennås Brante, E., \& Nyström, M. (2014). The Image of Images as an Aid to Improve Learning: An Eye-Tracking Experiment Studying the Effect of Contrasts in Computer-Based Learning Material. In S. Zvacek, M. T. Restivo, J. O. Uhomoibni, \& M. Helfert (Eds.), Proceedings of 6th International Conference on Computer Supported Education, CSEDU 2014 (Vol. 3, 309-316). Barcelona: SciTe Press. 
James, W. (1907/2014). Pragmatism. A New Name for Some Old Ways of Thinking. Cambridge: Cambridge University Press. http://dx.doi.org/10.1017/CBO9781107360471.003

Krikeben, G. (2010). Descartes Embodies Psychology: Descartes or Damasios Error? Journal of the History of the Neurosciences: Basic and Clinical Perspectives, 10, 173-191.

Kullberg, A. (2010). What Is Taught and What Is Learned. Professional Insights Gained and Shared by Teachers of Mathematics. Göteborg: Acta Universitatis Gothoburgensis.

Lewis, C., Perry, R., \& Murata, A. (2006). How Should Research Contribute to Instructional Improvement? The Case of Lesson Study. Educational Researcher, 31, 3-14. http://dx.doi.org/10.3102/0013189X035003003

Ling, L. M., \& Marton, F. (2012). Towards a Science of the Art of Teaching. Using Variation Theory as a Guiding Principle of Pedagogical Design. International Journal for Lesson and Learning Studies, 1, 7-22. http://dx.doi.org/10.1108/20468251211179678

Lo, M. L. (2012). Variation Theory and the Improvement of Teaching and Learning. Göteborg: Acta Universitatis Gothoburgensis.

Marton, F. (2014). Necessary Conditions of Learning. New York: Routledge.

Marton, F., \& Booth, S. (1997). Learning and Awareness. Mahwah, NJ: Lawrence Erlbaum Associates.

Marton, F., \& Pang, M. F. (2005). Learning Theory as Teaching Resource: Enhancing Students' Understanding of Economic Concepts. Instructional Science, 33, 159-191. http://dx.doi.org/10.1007/s11251-005-2811-0

Marton, F., \& Tsui, A. B. M. (2004). Classroom Discourse and the Space of Learning. Mahwah, NJ: Lawrence Erlbaum Associates.

McKenney, S., \& Reeves, T. C. (2012). Conducting Educational Design Research. New York: Routledge.

Morgan, D. (2014). Pragmatism as a Paradigm for Social Research. Qualitative Inquiry, 20, 1045-1053. http://dx.doi.org/10.1177/1077800413513733

National Agency of Education (2011).Skolverket: Läroplaner [National Agency of Education: Curriculum]. www.skolverket.se/laroplaner-amnen-ochkurser/grundskoleutbildning/grundskola/engelska

Pang, M. F., \& Lo, M. L. (2011). Learning Study: Helping Teachers to Use Theory, Develop Professionally, and Produce New Knowledge to Be Shared. Instructional Science, 40, 589-606. http://dx.doi.org/10.1007/s11251-011-9191-4

Pring, R. (2015). Philosophy of Educational Research. London: Bloomsbury.

Runesson, U., Kullberg, A., \& Maunula, T. (2011). Sensitivity to Student Learning-A Possible Way of Learning to Enhance Learning? In O. Zaslawski, \& P. Sullivan (Eds.), Constructing Knowledge for Teaching Secondary Mathematics: Tasks to Enhance Prospective and Practicing Teacher Learning (pp. 263-278). New York: Springer. http://dx.doi.org/10.1007/978-0-387-09812-8 16

Selin, P., \& Holmqvist Olander, M. (2015). Transformning New Curriculum Objectives into Classroom Instruction with the Aid of Learning Studies. International Journal for Lesson and Learning Studies, 4, 401-415. http://dx.doi.org/10.1108/IJLLS-01-2015-0006

Shawer, S. (2010). Communicative-Based Curriculum Innovations between Theory and Practice: Implications for EFL Curriculum Development and Student Cognitive and Affective Change. The Curriculum Journal, 21, 333-359. http://dx.doi.org/10.1080/09585176.2010.506802

Sundin, O., \&. Johannisson, J. (2005). Pragmatism, Neo-Pragmatism and Sociocultural Theory: Communicative Participants as a Perspective in LIS. Journal of Documentation, 61, 23-43. http://dx.doi.org/10.1108/00220410510577998

Wolf, M. K., Farnsworth, T., \& Herman, J. (2008).Validity Issues in Assessing English Language Learners’ Language Proficiency. Educational Assessment, 13, 80-107. http://dx.doi.org/10.1080/10627190802394222

Yin, R. (2014). Case Study Research. Design and Methods. Los Angeles: SAGE. 


\section{Submit or recommend next manuscript to SCIRP and we will provide best service for you:}

Accepting pre-submission inquiries through Email, Facebook, LinkedIn, Twitter, etc.

A wide selection of journals (inclusive of 9 subjects, more than 200 journals)

Providing 24-hour high-quality service

User-friendly online submission system

Fair and swift peer-review system

Efficient typesetting and proofreading procedure

Display of the result of downloads and visits, as well as the number of cited articles

Maximum dissemination of your research work

Submit your manuscript at: http://papersubmission.scirp.org/ 